\title{
Mode and place of delivery, gastrointestinal microbiota, and their influence on asthma and atopy.
}

Citation for published version (APA):

van Nimwegen, F. A., Penders, J., Stobberingh, E. E., Postma, D. S., Koppelman, G. H., Kerkhof, M., Reijmerink, N. E., Dompeling, E., van den Brandt, P. A., Ferreira, I., Mommers, M., \& Thijs, C. (2011). Mode and place of delivery, gastrointestinal microbiota, and their influence on asthma and atopy. Journal of Allergy and Clinical Immunology, 128(5), 948-955. https://doi.org/10.1016/j.jaci.2011.07.027

Document status and date:

Published: 01/11/2011

DOI:

10.1016/j.jaci.2011.07.027

Document Version:

Publisher's PDF, also known as Version of record

Document license:

Taverne

Please check the document version of this publication:

- A submitted manuscript is the version of the article upon submission and before peer-review. There can be important differences between the submitted version and the official published version of record.

People interested in the research are advised to contact the author for the final version of the publication, or visit the DOI to the publisher's website.

- The final author version and the galley proof are versions of the publication after peer review.

- The final published version features the final layout of the paper including the volume, issue and page numbers.

Link to publication

\footnotetext{
General rights rights.

- You may freely distribute the URL identifying the publication in the public portal. please follow below link for the End User Agreement:

www.umlib.nl/taverne-license

Take down policy

If you believe that this document breaches copyright please contact us at:

repository@maastrichtuniversity.nl

providing details and we will investigate your claim.
}

Copyright and moral rights for the publications made accessible in the public portal are retained by the authors and/or other copyright owners and it is a condition of accessing publications that users recognise and abide by the legal requirements associated with these

- Users may download and print one copy of any publication from the public portal for the purpose of private study or research.

- You may not further distribute the material or use it for any profit-making activity or commercial gain

If the publication is distributed under the terms of Article $25 \mathrm{fa}$ of the Dutch Copyright Act, indicated by the "Taverne" license above, 


\title{
Mode and place of delivery, gastrointestinal microbiota, and their influence on asthma and atopy
}

\author{
Frederika A. van Nimwegen, MSc, ${ }^{a}$ John Penders, PhD, ${ }^{a, b}$ Ellen E. Stobberingh, PhD, ${ }^{b}$ Dirkje S. Postma, MD, PhD, \\ Gerard H. Koppelman, MD, PhD, ${ }^{d}$ Marjan Kerkhof, MD, PhD, ${ }^{e}$ Naomi E. Reijmerink, MD, PhD, ${ }^{c, f}$ \\ Edward Dompeling, MD, PhD, ${ }^{\mathrm{g}}$ Piet A. van den Brandt, PhD, ${ }^{\mathrm{h}}$ Isabel Ferreira, PhD, ${ }^{\mathrm{i}, \mathrm{j}}$ Monique Mommers, PhD, ${ }^{\mathrm{a}}$ and \\ Carel Thijs, MD, PhD ${ }^{\mathbf{a}}$ Maastricht and Groningen, The Netherlands
}

Background: Both gastrointestinal microbiota composition and cesarean section have been linked to atopic manifestations. However, results are inconsistent, and the hypothesized intermediate role of the microbiota in the association between birth mode and atopic manifestations has not been studied yet. Objectives: We sought to investigate the relationship between microbiota composition, mode and place of delivery, and atopic manifestations.

Methods: The Child, Parent and Health: Lifestyle and Genetic Constitution Birth Cohort Study included data on birth characteristics, lifestyle factors, and atopic manifestations collected through repeated questionnaires from birth until age 7 years. Fecal samples were collected at age 1 month $(n=1176)$ to determine microbiota composition, and blood samples were collected at ages $1(n=921), 2(n=822)$, and 6 to $7(n=384)$ years to determine specific IgE levels.

Results: Colonization by Clostridium difficile at age 1 month was associated with wheeze and eczema throughout the first 6 to 7 years of life and with asthma at age 6 to 7 years. Vaginal home delivery compared with vaginal hospital delivery was associated with a decreased risk of eczema, sensitization to food allergens, and asthma. After stratification for parental history of atopy, the decreased risk of sensitization to food allergens (adjusted

\footnotetext{
From the Departments of ${ }^{\mathrm{a}}$ Epidemiology, ${ }^{\mathrm{b}}$ Medical Microbiology, ${ }^{\mathrm{g}}$ Pediatric Pulmonol ogy, ${ }^{\mathrm{i} C}$ Cinical Epidemiology and Medical Technology Assessment, and ${ }^{\mathrm{j}}$ Internal Medicine, CAPHRI School for Public Health and Primary Care, Maastricht University Medical Centre+; the Departments of ${ }^{\mathrm{c}}$ Pulmonology and ${ }^{\mathrm{d}}$ Pediatric Pulmonology and Pediatric Allergology, Beatrix Children's Hospital, and 'the Department of Epidemiology, University Medical Center Groningen, University of Groningen; ${ }^{\mathrm{f}}$ Beatrix Children's Hospital, University Medical Center Groningen, University of Groningen; and ${ }^{\mathrm{h}}$ the Department of Epidemiology, School for Oncology and Developmental Biology (GROW), Maastricht University Medical Centre+.

Supported by the Netherlands Asthma Foundation (grant no. 3.2.07.022 \& 3.2.03.48), the Stichting Astma Bestrijding, and the Dutch Biobanking and Biomolecular Resources Infrastructure (BBMRI-NL).

Disclosure of potential conflict of interest: D. S. Postma has consultant arrangements with Nycomed and has received research support from Topinstitute Pharma and AstraZeneca. G. H. Koppelman has received honoraria and research support from GlaxoSmithKline. C. Thijs has received research support from the Netherlands Asthma Foundation. The rest of the authors have declared that they have no conflict of interest.

Received for publication February 6, 2011; revised June 22, 2011; accepted for publication July 7, 2011

Available online August 27, 2011.

Corresponding author: John Penders, PhD, Maastricht University, Departments of Epidemiology \& Medical Microbiology, PO Box 616, 6200 MD Maastricht, The Netherlands. E-mail: j.penders@maastrichtuniversity.nl.

0091-6749/\$36.00

(C) 2011 American Academy of Allergy, Asthma \& Immunology

doi:10.1016/j.jaci.2011.07.027
}

odds ratio, $0.52 ; 95 \% \mathrm{CI}, 0.35-0.77$ ) and asthma (adjusted odds ratio, $0.47 ; 95 \% \mathrm{CI}, 0.29-0.77$ ) among vaginally home-born infants was only found for children with atopic parents. Mediation analysis showed that the effects of mode and place of delivery on atopic outcomes were mediated by $C$ difficile colonization.

Conclusion: Mode and place of delivery affect the gastrointestinal microbiota composition, which subsequently influences the risk of atopic manifestations. (J Allergy Clin Immunol 2011;128:948-55.)

Key words: Mode of delivery, cesarean section, hospital delivery, gastrointestinal microbiota composition, wheeze, eczema, asthma, atopy, mediation analysis, cohort study, KOALA study

Perturbations in the microbial colonization of an infant's gastrointestinal tract have been associated with an increased risk of atopic diseases in early life. ${ }^{1-4}$ These alterations, such as a delayed colonization with beneficial bacteria, might interfere with the development of immunologic tolerance. The absence of a proper immunosuppressive mechanism by regulatory $\mathrm{T}$ cells can result in an imbalance between $\mathrm{T}_{\mathrm{H}} 1$ and $\mathrm{T}_{\mathrm{H}} 2$ cells and, in turn, $\mathrm{T}_{\mathrm{H}} 1$ or $\mathrm{T}_{\mathrm{H}} 2$-mediated inflammatory diseases. ${ }^{5,6}$ Both cross-sectional and longitudinal studies have reported differences in gastrointestinal microbiota (GM) composition between allergic and nonallergic children. ${ }^{1-3,7}$ Within the Child, Parent and Health: Lifestyle and Genetic Constitution (KOALA) Birth Cohort Study, we have previously found an association between GM composition and eczema, recurrent wheeze, and allergic sensitization in the first 2 years of life, ${ }^{4,8}$ but the influence on the development of atopic diseases later in life, such as asthma, has not been studied yet.

Another perinatal risk factor for an increased risk of atopic disease is cesarean section, as shown in 2 meta-analyses conducted in 2008 by Bager et $\mathrm{al}^{9}$ and Thavagnanam et $\mathrm{al}^{10}$ (pooled odds ratios [ORs] of 1.18 [95\% CI, 1.05-1.32] and 1.20 [95\% CI, 1.14-1.26], respectively). There is evidence suggesting that cesarean section not only increases the risk of asthma but also of other allergic diseases, such as food allergy. ${ }^{9}$

It has been suggested that the neonatal GM composition has an intermediate role in the relationship between delivery characteristics and the development of atopic disease. This is based on the fact that children born by means of cesarean section are not exposed to their mother's vaginal and fecal bacteria, unlike children born vaginally. In a recent study on the bacterial composition of the skin, oral mucosa, and gut, vaginally delivered infants 
Abbreviations used

aOR: Adjusted odds ratio

GM: Gastrointestinal microbiota

KOALA: Child, Parent and Health: Lifestyle and Genetic Constitution

OR: Odds ratio

harbored bacterial communities that were most similar in composition to the vaginal communities of the mothers, whereas infants delivered by means of cesarean section lacked bacteria from their mother's vaginas. ${ }^{11}$

Initially, children born by means of cesarean section are colonized by bacteria originating from the hospital environment and nonmaternal skin bacteria, ${ }^{11-13}$ resulting in a delayed colonization of the gut by beneficial bacteria and a different bacterial composition compared with that seen in vaginally delivered infants. Infants born by means of cesarean section have an especially lower abundance of Bifidobacterium and Bacteroides species and are more frequently colonized by Clostridium diffcile. ${ }^{12,14,15}$ The place of delivery has an additionally important effect on the establishment of the GM composition because infants born vaginally in a hospital have a different GM composition, including more $C$ difficile, compared with home-born infants. ${ }^{11,14}$

Although the GM is hypothesized to constitute an intermediate factor in the causal pathway between delivery characteristics and atopic diseases, this intermediate role has not been studied. We therefore investigated whether GM composition and mode and place of delivery are associated with the development of atopic manifestations, including asthma in childhood. Additionally, we investigated whether the GM composition is an intermediate factor in the relationship between mode and place of delivery and the development of atopic manifestations.

\section{METHODS}

\section{Study population and design}

The KOALA study is a prospective birth cohort study enrolling pregnant women at 34 weeks of gestation. From an existing cohort, 2343 healthy pregnant women with a conventional lifestyle were recruited. ${ }^{16}$ Furthermore, 491 women with alternative lifestyles regarding child-rearing practices, dietary habits, restricted use of medication, and vaccination schemes were included in the cohort. Newborns with congenital abnormalities (eg, Down syndrome) and premature newborns (gestational age, $<37$ weeks) were excluded. Children who received antibiotics in the first month of life were excluded from the analyses that included GM composition. More details of the study population and methods have been described previously. ${ }^{17}$

Questionnaires on demographic and perinatal and lifestyle factors were sent to all parents at 34 weeks of gestation and at $3,7,12$, and 24 months and at 4 to 5 and 6 to 7 years postpartum. The questionnaires from 7 months postpartum and onward included questions adapted from the International Study of Asthma and Allergies in Childhood to collect data on atopic manifestations and wheeze. ${ }^{18}$ Parents recruited from January 2002 onward were also asked for informed consent for sampling the feces of the child at the age of 1 month postpartum $(n=1176)$ to determine gastrointestinal microbial composition. Children in this subgroup, if still participating, were also eligible for blood sampling at the ages of 1,2, and 6 to 7 years to determine specific IgE levels.

Informed consent forms were signed by all parents. The KOALA study was approved by the Medical Ethical Committee of the Maastricht University/ University Hospital of Maastricht and the National Ethical Committee for Medical Research.

\section{Microbial analysis}

Infants' fecal samples were collected at age 1 month by their parents and immediately sent to the laboratory by post. The methods of fecal sampling and subsequent DNA extraction have been described in detail elsewhere. ${ }^{14}$

Fecal samples were subjected to real-time PCR for detection of Bifidobacterium species, Escherichia coli, $C$ difficile, Bacteroides fragilis group, and Lactobacillus species. $^{14}$

\section{Definition of mode and place of delivery}

Mode and place of delivery were measured in the 3-month postpartum questionnaire as "vaginal delivery at home," "vaginal delivery in the hospital," or "cesarean section delivery in the hospital." Artificial deliveries (eg, use of forceps or vacuum pump) were considered vaginal delivery in the hospital because those deliveries took place in a hospital.

\section{Definition of parentally reported atopic outcomes}

The presence of asthma, wheeze, and eczema was based on parentally completed questionnaires on atopic symptoms adapted from the International Study of Asthma and Allergies in Childhood questionnaire. ${ }^{18}$

Asthma at the age of 6 to 7 years was defined as a parentally reported doctor's diagnosis of asthma in combination with clinical symptoms in the last 12 months or having used asthma medications in the last 12 months. Clinical symptoms were defined as at least 1 attack of wheeze or dyspnea. Asthma medication was defined as regular use of short-acting bronchodilators or use of inhaled corticosteroids according to the Dutch guidelines of treatment of bronchial asthma in children. Regular use was defined as everyday use for a period of at least 2 months during the last 12 months or use associated with the physical activity of the child. ${ }^{19}$

The presence of wheeze was defined as parentally reported wheeze since the last follow-up moment for questionnaires in the first year of life (questionnaires at 7 and 12 months) and in the last 12 months for questionnaires after the first year of life (24 months, 4-5 years, and 6-7 years).

Children were regarded as having eczema when their parents provided an affirmative answer to the following question: "Did your child suffer from an itchy rash that was coming and going over the last 12 months (or since the last followup in the first year of life)?" Children for whom only diaper rash, rash around the eyes, and/or scalp scaling was reported were not regarded as having had eczema. Eczema was measured at 7, 12, and 24 months and 6 to 7 years of age.

\section{Determination of atopic sensitization}

At 1 year postpartum, infants' capillary blood spots were collected during home visits. Levels of specific IgE against hen's eggs, cow's milk, and peanut were measured as described earlier, ${ }^{20,21}$ with modifications to accommodate the use of capillary blood samples. ${ }^{22}$ The detection limit for specific IgE was less than $0.36 \mathrm{IU} / \mathrm{mL}$. Children were considered sensitized if specific serum IgE levels were greater than the detection limit for at least 1 allergen.

At 2 and 6 to 7 years postpartum, children's venous blood samples were collected during home visits and stored at $-80^{\circ} \mathrm{C}$ until analysis. Samples were analyzed for specific IgE against hen's egg, cow's milk, peanut, birch, grass pollen, cat, dog, and house dust mite by using RASTs, as described earlier. ${ }^{23}$ The detection limit for specific IgE was $0.10 \mathrm{IU} / \mathrm{mL}$. Children were considered sensitized if specific serum IgE levels were greater than $0.35 \mathrm{IU} / \mathrm{mL}$ against at least 1 allergen.

All IgE measurements were done by Sanquin Research (Amsterdam, The Netherlands).

\section{Statistical analyses}

Logistic regression models were used to estimate unadjusted and adjusted odds ratios (ORs) with 95\% CIs for the outcome of asthma at 6 to 7 years.

Generalized estimating equation models with exchangeable correlation structures were used for the repeated outcome measurements of eczema, wheeze, and sensitization to food and inhalant allergens.

Because participants were recruited from 2 different sources (conventional and alternative recruitment groups), interaction between main determinants 


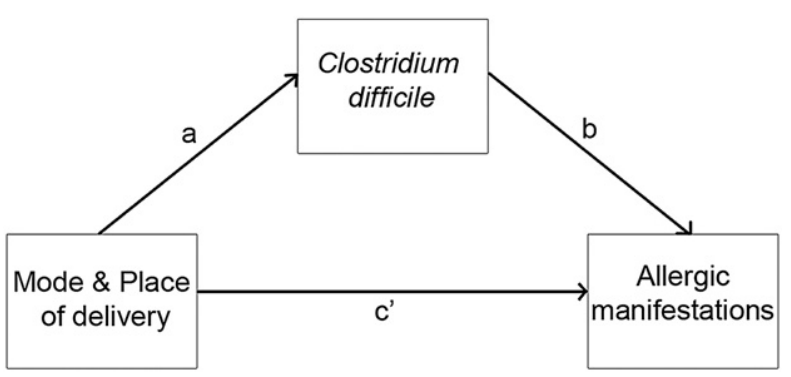

FIG 1. Mediation model. The relation between the antecedent variable mode of delivery on the dependent variable allergic manifestations is mediated through $C$ difficile. a Represents the strength of the relation between mode of delivery and $C$ difficile, $b$ represents the strength of the association between $C$ difficile and the allergic outcomes, and $c^{\prime}$ represents the strength of the relation between mode of delivery and the allergic outcomes.

and the recruitment group was tested in all models. Because none of the interaction terms reached statistical significance, the groups were combined and treated as 1 cohort in the analyses.

The following variables were included in the analyses to control for potential confounding: recruitment group (conventional, alternative), sex (male, female), birth weight (in grams), breast-feeding (never, 0-3 months, 3-6 months, $>6$ months of breast-feeding), maternal smoking during pregnancy (yes, no), maternal age at estimated date of delivery (in years), highest achieved maternal education level (low: primary school, preparatory vocational or lower general secondary education; middle: vocational education, higher general secondary or preuniversity education; high: higher vocational or academic education), and age at collection fecal sample (in days). Furthermore, we controlled for siblings' atopic history, which was defined as parent-reported doctor-diagnosed food allergy, eczema, hay fever, asthma, and pet and/or house dust mite allergy (no siblings; $\geq 1$ sibling, none atopic; or $\geq 1$ sibling, at least 1 atopic).

Because previous studies have shown an effect modification by parental history of atopy, ${ }^{24-26}$ all analyses were conducted both unstratified and stratified for parental history of atopy. In the unstratified analyses parental atopic history was included as an additional confounder. Parental history of atopy was defined as follows: self-reported doctor-diagnosed eczema, hay fever, asthma, and pet and/or house dust mite allergy (no atopic parent; at least 1 parent atopic) were taken into account.

SPSS 15.0 for Windows (SPSS, Inc, Chicago, Ill) was used to perform the statistical analyses. $P$ values of less than .05 were considered statistically significant.

To investigate whether $C$ difficile mediated the associations between mode of delivery and the atopic manifestations, we used the $a b$ product coefficient method. This entails estimating the product of 2 coefficients: that of the association between mode of delivery and $C$ difficile (the $a$ path) and that of the association between $C$ difficile and study outcomes (the $b$ path, Fig 1$).{ }^{27}$ We obtained standardized coefficients and SEs in these analyses. ${ }^{27}$ These data were then entered into the RMediation package written for use in the R statistical software program to calculate $95 \%$ CIs around the $a b$ estimate. ${ }^{28}$ The $a b$ estimate indicates the magnitude of the mediated or indirect "effect," which is significant if 0 is not included in the CI. Note that we used the method of distribution of the product to estimate the $95 \% \mathrm{CI}$; this yields asymmetric confidence limits to properly reflect the distribution of the $a b$ estimate, which is often skewed. ${ }^{27}$

All mediation analyses were confined to the subsets of study participants, with complete data on the 3 primary variables considered in each model (ie, mode of delivery, $C$ difficile, and study outcome).

\section{RESULTS}

Of the 2834 children enrolled in the cohort, 8 were excluded because of congenital abnormalities, 91 because of prematurity (gestational age, $<37$ weeks), and 2 because of both, resulting in 2733 children included in the study (Fig E1 in this article's Online
Repository at www.jacionline.org). Table I shows the baseline characteristics for the total study cohort, the children for whom the 6- to 7-year questionnaire was available $(\mathrm{n}=1926)$, and the children from whom an appropriate fecal sample was received at age 1 month $(n=952)$. Because recruitment of the alternative group coincided with the start of biosampling, the subgroup from whom fecal samples had been collected consisted of a higher proportion of participants from the alternative recruitment group than the group recruited earlier. This difference is also reflected in the duration of breast-feeding, smoking during pregnancy, and maternal educational level.

At age 6 to 7 years, $6.9 \%$ (133/1915) of the children had parentreported asthma. At the age of 12 months, the prevalence of wheeze was $16.9 \%$ and decreased with age to $8.0 \%$ at age 6 to 7 years (see Fig E2 in this article's Online Repository at www. jacionline.org). For eczema, the prevalence peaked at 24 months at $23.3 \%$ and decreased to $12.4 \%$ at age 6 to 7 years (see Fig E3 in this article's Online Repository at www.jacionline.org). At the age of 1 year, $13.9 \%$ of the children were sensitized to food allergens compared with $21.5 \%$ and $21.6 \%$ at the ages of 2 and 6 to 7 years, respectively. Sensitization to inhalant allergens increased from $10.7 \%$ at age 2 years to $28.9 \%$ at age 6 to 7 years.

\section{GM composition and atopic outcomes}

Birthplace and mode were strongly associated with colonization by $C$ difficile: colonization rates for vaginally home-born, vaginally hospital-born, and cesarean section-delivered children were $19.1 \%, 27.2 \%$, and $43.4 \%$, respectively $\left(P_{\text {trend }}<.001\right)$.

$C$ difficile was also the single gut microbe investigated that was associated with an increased risk for asthma (adjusted odds ratio [aOR], 2.06; 95\% CI, 1.16-3.64; Table II). Stratified results showed that this association was restricted to those children with atopic parents (aOR, 2.27; 95\% CI, 1.22-4.21).

The previously reported associations between the presence of $C$ difficile in the feces at 1 month postpartum and the development of wheeze, eczema, and sensitization to food allergens in the first 2 years of life ${ }^{4}$ were also found in this study and persisted throughout the first 7 years of life (Tables II and III). For eczema and sensitization to food allergens, we also found that the association with $C$ difficile was limited to children with a family history of atopy, whereas the association between this bacterium and wheeze was more pronounced in the children without atopic parents.

None of the other bacterial species and genera under study were associated with the atopic outcomes in either the unstratified (Tables II and III) or stratified (data not shown) analysis.

\section{Mode and place of delivery and atopic outcomes}

Children with at least 1 atopic parent who were born vaginally at home had a lower odds of having asthma than children born vaginally at the hospital (reference category; aOR, 0.47; 95\% CI, 0.29-0.77; Table IV). The risk of asthma for children born by means of cesarean section did not differ significantly compared with that of children born vaginally in the hospital. These associations were absent in children without atopic parents.

Vaginal hospital delivery was also associated with a reduced risk of eczema in the period between 0 and 7 years, although results were only statistically significant in the unstratified analyses. No significant associations were found between the mode and place of delivery and wheeze (Table IV). 


\begin{tabular}{|c|c|c|c|c|c|c|}
\hline & \multicolumn{2}{|c|}{$\begin{array}{l}\text { Total study cohort } \\
\quad(n=2733)\end{array}$} & \multicolumn{2}{|c|}{$\begin{array}{l}\text { Children with question- } \\
\text { naire at 6-7 y available } \\
(n=1926)\end{array}$} & \multicolumn{2}{|c|}{$\begin{array}{c}\text { Children with GM } \\
\text { composition determined } \\
\text { ( } \mathrm{n}=952)\end{array}$} \\
\hline & No.* & Percent & No.* & Percent & No.* & Percent \\
\hline \multicolumn{7}{|l|}{ Mode and place of delivery } \\
\hline Vaginal at home & 1179 & 46.1 & 862 & 46.0 & 450 & 48.3 \\
\hline Vaginal in hospital & 1092 & 42.7 & 795 & 42.4 & 382 & 41.0 \\
\hline Cesarean section & 288 & 11.2 & 216 & 11.5 & 99 & 10.6 \\
\hline Maternal atopy (yes) & 986 & 37.4 & 712 & 37.3 & 368 & 38.7 \\
\hline Paternal atopy (yes) & 959 & 36.7 & 697 & 36.5 & 361 & 38.2 \\
\hline \multicolumn{7}{|l|}{ Siblings with atopy } \\
\hline No siblings & 2170 & 83.0 & 1599 & 83.7 & 789 & 82.9 \\
\hline No atopic siblings & 319 & 12.2 & 225 & 11.8 & 101 & 10.6 \\
\hline$\geq 1$ Atopic sibling & 126 & 4.8 & 87 & 4.5 & 61 & 6.4 \\
\hline$>6 \mathrm{mo}$ & 858 & 32.8 & 677 & 35.8 & 388 & 41.4 \\
\hline \multicolumn{7}{|l|}{ Maternal education level } \\
\hline Low & 274 & 10.2 & 154 & 8.1 & 68 & 7.2 \\
\hline Middle & 1125 & 41.7 & 756 & 39.8 & 345 & 36.6 \\
\hline High & 1299 & 48.1 & 991 & 52.1 & 529 & 56.2 \\
\hline \multirow[t]{2}{*}{ Smoking during pregnancy (yes) } & 198 & 7.2 & 98 & 5.1 & 35 & 3.7 \\
\hline & Mean & SD & Mean & SD & Mean & SD \\
\hline Maternal age at delivery (y) & 32.0 & 3.79 & 32.3 & 3.71 & 32.7 & 3.85 \\
\hline Birth weight (g) & 3537.1 & 476.3 & 3549.3 & 467.9 & 3562.5 & 459.9 \\
\hline
\end{tabular}

*Numbers might not add up to the total number because of missing values.

In children with a positive family history of atopy, vaginal home delivery decreased the odds for sensitization to food allergens (aOR, 0.52; 95\% CI, 0.35-0.77) compared with vaginal birth in the hospital. The odds of sensitization to food allergens did not differ significantly between children born by means of cesarean section or born vaginally in the hospital (Table V).

In contrast to sensitization to food allergens, mode and place of delivery were not associated with sensitization to inhalant allergens (Table V), although it has to be noted that these latter analyses showed a statistically significant interaction with time, meaning that results differed for sensitization at the different time points (2 and 6-7 years, respectively). Further analyses showed that, although not statistically significant, home delivery tended toward decreased risk of sensitization to inhalant allergens in children with atopic parents only at age 6 to 7 years (aOR, 0.65; 95\% CI, 0.35-1.21).

\section{Mediation analyses}

Because mode and place of delivery strongly influence $C$ difficile colonization and this bacterium is also associated with the atopic manifestations under study, colonization by $C$ difficile might act as an intermediate factor in the association between birth mode and atopic diseases.

Mediation analyses (Table VI) indeed showed that $C$ difficile mediated the relation between mode and place of delivery and both asthma and eczema. Statistically significant $a b$ crossproducts were found not only for birthplace in relation to these atopic outcomes but also for birth mode (cesarean section vs vaginal hospital delivery).

Although stratified analyses did not always show statistically significant $a b$ cross-products in the group with parental atopy, the direction and order of magnitude were comparable with the overall analyses. Additional adjustment for the confounders included in previous analyses (Tables II-V) generated similar results (data not shown).

\section{DISCUSSION}

In this prospective birth cohort study, colonization with $C$ difficile was associated with an increased risk of asthma at 6 to 7 years of age and wheeze, eczema, and sensitization to food allergens until the age of 6 to 7 years. Furthermore, in children with a positive family history of atopy, vaginal home delivery was associated with a decreased risk of asthma and sensitization to food allergens when compared with vaginal hospital delivery. Results for sensitization to inhalant allergens show the same trend as the results for asthma; however, they lacked statistical significance. It has to be noted that the group for whom venous blood was available was much smaller than the group for whom questionnaire data were available, thereby resulting in a lower power.

The associations found between colonization with $C$ difficile and atopic manifestations and the associations between mode and place of delivery and atopic manifestations are partly in line with the results of previous studies., ${ }^{9,24}$ Although metaanalyses showed a significant effect of delivery by means of 
TABLE II. Associations between GM composition and asthma, wheeze, and eczema

\begin{tabular}{|c|c|c|c|c|c|c|c|}
\hline & \multicolumn{3}{|c|}{ Asthma 6-7 $\mathrm{y}^{*}(\mathrm{n}=728)$} & \multicolumn{2}{|c|}{ Wheeze $\ddagger(n=942) \S$} & \multicolumn{2}{|c|}{ Eczema $\ddagger(n=942) \S$} \\
\hline & $\mathrm{n} / \mathrm{N}$ & cOR $(95 \% \mathrm{Cl})$ & $\mathrm{aOR}+(95 \% \mathrm{Cl})$ & cOR $(95 \% \mathrm{Cl})$ & $\mathrm{aOR}+(95 \% \mathrm{Cl})$ & cOR $(95 \% \mathrm{Cl})$ & aOR† $(95 \% \mathrm{Cl})$ \\
\hline \multicolumn{8}{|c|}{$C$ difficile (unstratified) } \\
\hline \multicolumn{8}{|l|}{ Parental atopy } \\
\hline \multicolumn{8}{|l|}{$C$ difficile } \\
\hline$-($ reference $)$ & $27 / 325$ & 1 & 1 & 1 & 1 & 1 & 1 \\
\hline \multicolumn{8}{|l|}{$C$ difficile } \\
\hline$-($ reference $)$ & $8 / 222$ & 1 & 1 & 1 & 1 & 1 & 1 \\
\hline+ & $2 / 54$ & $1.02(0.21-4.97)$ & $1.11(0.22-5.66)$ & $1.73(1.03-2.90) \|$ & $1.82(1.09-3.05) \|$ & $1.20(0.71-2.02)$ & $1.23(0.73-2.08)$ \\
\hline \multicolumn{8}{|c|}{$\begin{array}{l}\text { Bifidobacterium species } \\
\text { (unstratified) }\end{array}$} \\
\hline- (reference) & $2 / 9$ & 1 & 1 & 1 & 1 & 1 & 1 \\
\hline+ & $53 / 640$ & $1.45(0.56-3.73)$ & $1.16(0.44-3.05)$ & $1.33(0.88-2.02)$ & $1.22(0.81-1.84)$ & $1.15(0.75-1.74)$ & $1.10(0.72-1.67)$ \\
\hline \multicolumn{8}{|l|}{$\begin{array}{l}\text { Bacteroides fragilis } \\
\text { (unstratified) }\end{array}$} \\
\hline$-($ reference $)$ & $8 / 135$ & 1 & 1 & 1 & 1 & 1 & 1 \\
\hline+ & $50 / 593$ & $1.46(0.68-3.17)$ & $1.49(0.68-3.26)$ & $0.88(0.65-1.18)$ & $0.89(0.66-1.21)$ & $1.02(0.75-1.39)$ & $1.03(0.76-1.40)$ \\
\hline \multicolumn{8}{|c|}{$\begin{array}{l}\text { Lactobacillus species } \\
\quad \text { (unstratified) }\end{array}$} \\
\hline- (reference) & $38 / 495$ & 1 & 1 & 1 & 1 & 1 & 1 \\
\hline+ & $20 / 233$ & $1.13(0.64-1.98)$ & $1.20(0.67-2.14)$ & $0.94(0.72-1.24)$ & $0.96(0.73-1.26)$ & $1.14(0.88-1.48)$ & $1.15(0.89-1.50)$ \\
\hline
\end{tabular}

Boldfaced text indicates statistically significant associations at $P<.05$.

- (reference), Colonization absent (reference category); + , colonization present; $C O R$, crude odds ratio.

*Logistic regression analyses.

$\dagger$ Adjusted for recruitment group, parental history of atopy (included only in unstratified analyses), sibling history of atopy, and age at collection of fecal sample and sex. TGeneralized estimating equations (measurements of wheeze at 7, 12, and 24 months and 4 to 5 and 6 to 7 years and eczema at 7,12 , and 24 months and 6 to 7 years). §Outcome data are available for at least 1 time point in generalized estimating equation analyses.

$\| P<.05$.

cesarean section on asthma risk, we only found a statistically significant association for the place of delivery (home vs hospital). Thus our results demonstrate, for the first time, that not only the mode but also especially the place of delivery play an important role in the development of atopic manifestations in childhood.

The associations between place of delivery on the one hand and asthma and sensitization to food allergens on the other hand were modified by parental atopic status. This effect-modifying role has also been shown previously regarding birth mode. ${ }^{24-26}$

We were not able to take head circumference into account. It has been shown that an increased head circumference is associated with increased IgE levels to inhalant allergens and asthma. ${ }^{29-31}$ Therefore increased head circumference could possibly cause confounding by indication because large head circumference increases the risk of obstetric complications and thus the chance of delivery by means of cesarean section. However, our finding that increased risks of atopic manifestations were also found for vaginal delivery in the hospital makes it unlikely that the associations between delivery by means of cesarean section and atopic diseases can be explained only by head circumference.

We investigated not only the separate associations between delivery characteristics and atopy development but also a hypothetical underlying mechanism. Mediation analyses confirmed an intermediate role for $C$ difficile in the association between mode and place of delivery and atopic outcomes. Statistically significant products of $a b$ coefficients were found for the outcomes asthma and eczema, whereas borderline significant results were found for the other outcomes. Notably, mediation was not only found for vaginal home delivery but also for cesarean section compared with vaginal hospital delivery in association with both asthma and eczema. This means that mediation exists for birth by cesarean section, whereas a significant relation between birth by cesarean section and atopic outcomes in the main analyses was not obtained. However, this is not uncommon; there are many cases in which significant mediation exists while a significant relation between the dependent and independent variables is not obtained. ${ }^{32}$

The findings of mediation by $C$ difficile strengthen the evidence for a causal role of birth mode on atopic manifestations through influencing the GM composition. The fact that mediation only party explained the association between delivery characteristics and atopic manifestations (associations remained significant after adjusting for $C$ difficile) might indicate that other intestinal microorganisms are also involved in this relationship.

We conclude that the mode and place of delivery affect the GM composition, which subsequently influences the risk of atopic manifestations, as demonstrated for $C$ difficile. These findings strengthen the evidence for a causal relationship between birth 
TABLE III. Associations between GM composition and sensitization to food and inhalant allergens

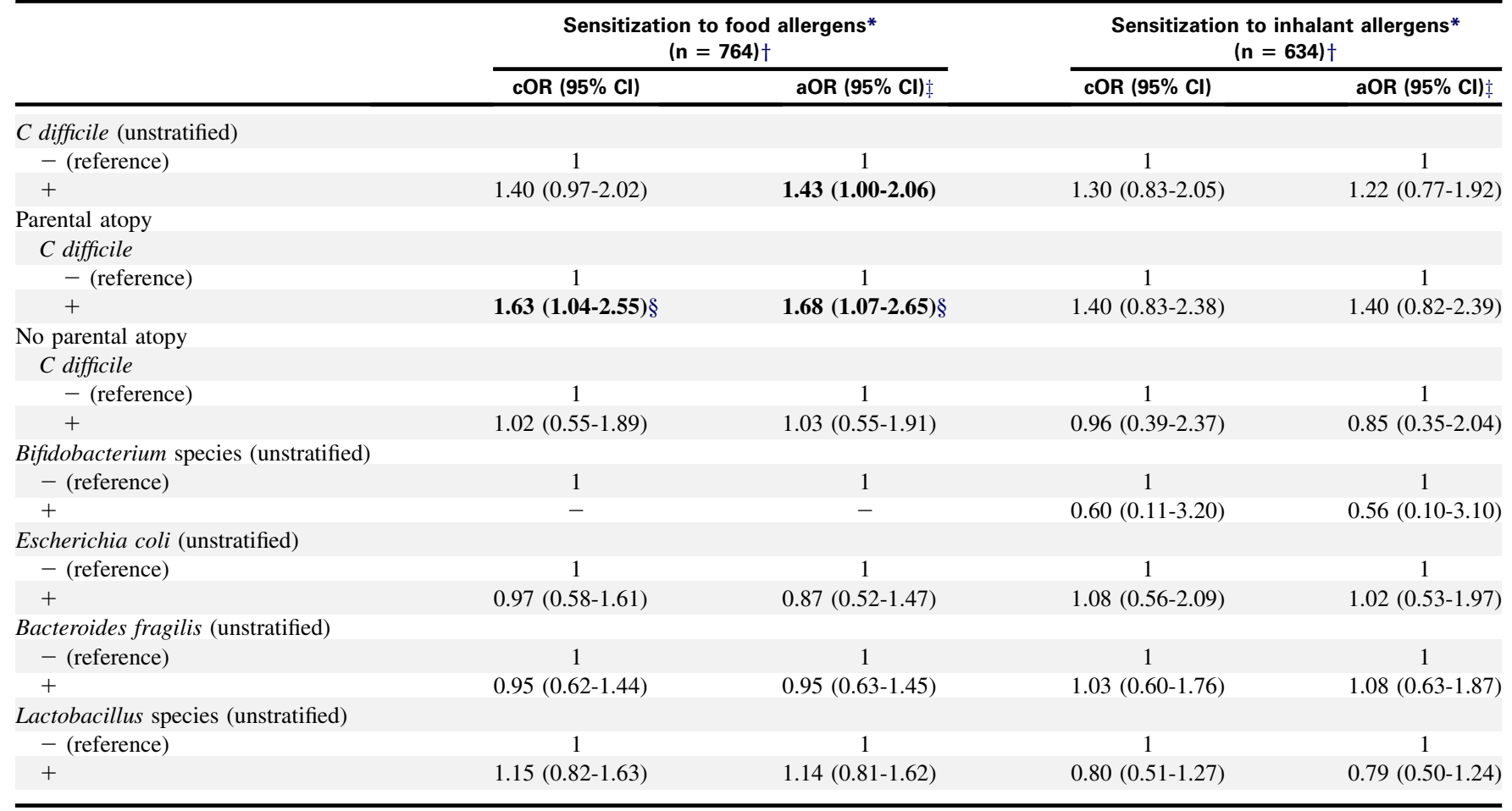

Boldfaced text indicates statistically significant associations at $P<.05$.

- (reference), Colonization absent (reference category); + , colonization present; $c O R$, crude odds ratio.

*Generalized estimating equations (measurements at 12 months [only food allergens], 24 months, and 6 to 7 years).

†Outcome data are available for at least 1 time point in generalized estimating equation analyses.

$\$$ Adjusted for recruitment group, parental history of atopy (included only in unstratified analyses), sibling history of atopy, age at collection of fecal sample, and sex.

$\S P<.05$.

TABLE IV. Association of mode and place of delivery with asthma, wheeze, and eczema

\begin{tabular}{|c|c|c|c|c|c|c|c|}
\hline & \multicolumn{3}{|c|}{ Asthma 6-7 $y^{*}(n=1862)$} & \multicolumn{2}{|c|}{ Wheeze $\ddagger(n=2534) \S$} & \multicolumn{2}{|c|}{ Eczema $\ddagger(n=2533) \S$} \\
\hline & $n / N$ & cOR $(95 \% \mathrm{Cl})$ & aOR $†(95 \% \mathrm{Cl})$ & cOR (95\% Cl) & aOR $†(95 \% \mathrm{Cl})$ & $\operatorname{cOR}(95 \% \mathrm{Cl})$ & aOR† $(95 \% \mathrm{Cl})$ \\
\hline \multicolumn{8}{|l|}{ Unstratified analyses } \\
\hline $\begin{array}{l}\text { Vaginal in the hospital } \\
\text { (reference) }\end{array}$ & $67 / 792$ & 1 & 1 & 1 & 1 & 1 & 1 \\
\hline Vaginal at home & $44 / 854$ & $0.59(0.40-0.88) \|$ & $0.59(0.40-0.89) \|$ & $0.86(0.73-1.01)$ & $0.88(0.74-1.04)$ & $0.84(0.71-0.99) \|$ & $0.84(0.71-1.00) \|$ \\
\hline Cesarean section & $17 / 216$ & $0.95(0.54-1.65)$ & $0.89(0.50-1.56)$ & $1.08(0.86-1.37)$ & $1.05(0.82-1.33)$ & $0.89(0.69-1.15)$ & $0.89(0.68-1.15)$ \\
\hline \multicolumn{8}{|l|}{ Stratified analyses } \\
\hline \multicolumn{8}{|l|}{ Parental atopy } \\
\hline $\begin{array}{l}\text { Vaginal in the hospital } \\
\text { (reference) }\end{array}$ & $51 / 448$ & 1 & 1 & & 1 & 1 & 1 \\
\hline Vaginal home & $29 / 515$ & $0.47(0.29-0.75) \|$ & $0.47(0.29-0.77) \|$ & $0.85(0.69-1.04)$ & $0.89(0.73-1.10)$ & $0.87(0.71-1.06)$ & $0.86(0.70-1.06)$ \\
\hline Cesarean section & $12 / 130$ & $0.78(0.40-1.52)$ & $0.80(0.41-1.57)$ & $1.02(0.76-1.35)$ & $1.02(0.77-1.36)$ & $0.77(0.56-1.07)$ & $0.80(0.57-1.11)$ \\
\hline \multicolumn{8}{|l|}{ No parental atopy } \\
\hline $\begin{array}{l}\text { Vaginal in the hospital } \\
\text { (reference) }\end{array}$ & $16 / 340$ & 1 & 1 & 1 & 1 & 1 & 1 \\
\hline Vaginal at home & $15 / 338$ & $0.95(0.46-1.96)$ & $1.03(0.49-2.14)$ & $0.84(0.63-1.12)$ & $0.85(0.63-1.15)$ & $0.79(0.60-1.04)$ & $0.80(0.60-1.06)$ \\
\hline Cesarean section & $5 / 81$ & $1.35(0.48-3.81)$ & $1.00(0.34-2.92)$ & $1.16(0.77-1.76)$ & $1.07(0.70-1.65)$ & $1.18(0.79-1.78)$ & $1.04(0.68-1.59)$ \\
\hline
\end{tabular}

Boldfaced text indicates statistically significant associations at $P<.05$.

cOR, Crude odds ratio.

*Logistic regression analyses.

$\dagger$ Analyses adjusted for recruitment group, sex, birth weight, breast-feeding, maternal age, maternal smoking during pregnancy, maternal education level, and siblings with atopy (and parental atopy in case of unstratified analyses).

†.Generalized estimating equations (measurements at 7,12 , and 24 months; 4-5 years [only wheeze]; and 6-7 years).

$\S$ Outcome data are available for at least 1 time point in generalized estimating equation analyses.

$\| P<.05$. 
TABLE V. Association of mode and place of delivery with sensitization to food and inhalant allergens

\begin{tabular}{|c|c|c|c|c|}
\hline & \multicolumn{2}{|c|}{$\begin{array}{l}\text { Sensitization to food allergens* } \\
(n=1087) \dagger\end{array}$} & \multicolumn{2}{|c|}{$\begin{array}{l}\text { Sensitization to inhalant allergens* } \\
(\mathbf{n}=867) \dagger\end{array}$} \\
\hline & cOR $(95 \% \mathrm{Cl})$ & $\mathrm{aOR} \ddagger(95 \% \mathrm{Cl})$ & cOR $(95 \% \mathrm{Cl})$ & $\mathrm{aOR} \ddagger(95 \% \mathrm{Cl})$ \\
\hline \multicolumn{5}{|l|}{ Unstratified analyses } \\
\hline Vaginal in the hospital (reference) & 1 & 1 & 1 & 1 \\
\hline Vaginal at home & $0.61(0.45-0.82) \S$ & $0.61(0.45-0.83) \S$ & $1.01(0.69-1.48)$ & $0.92(0.62-1.38)$ \\
\hline Cesarean section & $1.12(0.72-1.75)$ & $1.11(0.70-1.77)$ & $1.23(0.70-2.14)$ & $1.31(0.73-2.35)$ \\
\hline \multicolumn{5}{|l|}{ Stratified analyses } \\
\hline \multicolumn{5}{|l|}{ Parental atopy } \\
\hline Vaginal in the hospital (reference) & 1 & 1 & 1 & 1 \\
\hline Vaginal at home & $0.52(0.36-0.76) \S$ & $0.52(0.35-0.77) \S$ & $0.79(0.50-1.26)$ & $0.73(0.44-1.19)$ \\
\hline Cesarean section & $1.14(0.66-1.97)$ & $1.17(0.66-2.07)$ & $0.96(0.48-1.91)$ & $1.16(0.57-2.36)$ \\
\hline \multicolumn{5}{|l|}{ No parental atopy } \\
\hline Vaginal in the hospital (reference) & 1 & 1 & 1 & 1 \\
\hline Vaginal at home & $0.76(0.47-1.25)$ & $0.83(0.51-1.36)$ & $1.41(0.71-2.82)$ & $1.46(0.71-3.02)$ \\
\hline Cesarean section & $1.02(0.47-2.21)$ & $0.98(0.42-2.26)$ & $1.73(0.66-4.67)$ & $1.80(0.57-5.67)$ \\
\hline
\end{tabular}

Boldfaced text indicates statistically significant associations at $P<.05$.

$c O R$, Crude odds ratio.

*Generalized estimating equations (measurements at 12 months [only food allergens], 24 months, and 6-7 years).

†Outcome data are available for at least 1 time point in generalized estimating equation analyses.

$\ddagger$ Analyses adjusted for recruitment group, sex, birth weight, breast-feeding, maternal age, maternal smoking during pregnancy, maternal education level, and siblings with atopy (and parental atopy in case of unstratified analyses).

$\S P<.05$.

TABLE VI. Mediation of $C$ difficile in the association between mode and place of delivery and atopic outcomes

\begin{tabular}{|c|c|c|c|c|c|c|c|c|}
\hline \multirow[b]{2}{*}{ Dependent } & \multirow[b]{2}{*}{ Independent§ } & \multirow[b]{2}{*}{ Group } & \multicolumn{2}{|c|}{ a Path* } & \multicolumn{2}{|c|}{ b Path $†$} & \multicolumn{2}{|c|}{ Mediated effect $\ddagger$} \\
\hline & & & Coefficient & SE & Coefficient & $\mathrm{SE}$ & $\mathbf{a b}$ & $95 \% \mathrm{Cl}$ \\
\hline \multirow[t]{6}{*}{ Asthma } & Vaginal home delivery & All & -0.149 & 0.052 & 0.147 & 0.067 & $-\mathbf{0 . 0 2 2} \|$ & -0.052 to -0.001 \\
\hline & & Parental atopy + & -0.101 & 0.064 & 0.160 & 0.076 & -0.016 & -0.048 to 0.004 \\
\hline & & Parental atopy - & -0.259 & 0.092 & 0.006 & 0.182 & -0.001 & -0.105 to 0.101 \\
\hline & Cesarean section & All & 0.137 & 0.045 & 0.150 & 0.069 & $0.021 \|$ & 0.001 to 0.048 \\
\hline & & Parental atopy + & 0.164 & 0.056 & 0.167 & 0.079 & $0.027 \|$ & 0.001 to 0.065 \\
\hline & & Parental atopy - & 0.078 & 0.074 & 0.006 & 0.182 & 0.000 & -0.041 to 0.043 \\
\hline \multirow[t]{6}{*}{ Wheeze } & Vaginal home delivery & All & -0.126 & 0.045 & 0.058 & 0.034 & -0.007 & -0.019 to 0.001 \\
\hline & & Parental atopy + & -0.078 & 0.057 & 0.029 & 0.040 & -0.002 & -0.012 to 0.005 \\
\hline & & Parental atopy - & -0.217 & 0.077 & 0.114 & 0.063 & -0.025 & -0.064 to 0.002 \\
\hline & Cesarean section & All & 0.121 & 0.039 & 0.058 & 0.034 & 0.007 & -0.001 to 0.018 \\
\hline & & Parental atopy + & 0.138 & 0.050 & 0.029 & 0.040 & 0.004 & -0.007 to 0.017 \\
\hline & & Parental atopy - & 0.087 & 0.064 & 0.114 & 0.063 & 0.010 & -0.005 to 0.034 \\
\hline \multirow[t]{6}{*}{ Eczema } & Vaginal home delivery & All & -0.126 & 0.045 & 0.087 & 0.034 & $-0.011 \|$ & -0.025 to -0.001 \\
\hline & & Parental atopy + & -0.078 & 0.057 & 0.093 & 0.040 & -0.007 & -0.023 to 0.003 \\
\hline & & Parental atopy - & -0.217 & 0.077 & 0.053 & 0.057 & -0.011 & $-0.042 ;$ to 0.013 \\
\hline & Cesarean section & All & 0.121 & 0.039 & 0.087 & 0.034 & 0.011 $\|$ & 0.002 to 0.023 \\
\hline & & Parental atopy + & 0.138 & 0.050 & 0.094 & 0.041 & $0.013 \|$ & 0.001 to 0.030 \\
\hline & & Parental atopy - & 0.087 & 0.064 & 0.053 & 0.057 & 0.005 & -0.006 to 0.022 \\
\hline \multirow[t]{6}{*}{$\operatorname{IgE}$, food } & Vaginal home delivery & All & -0.126 & 0.045 & 0.062 & 0.045 & -0.008 & -0.023 to 0.003 \\
\hline & & Parental atopy + & -0.078 & 0.057 & 0.100 & 0.057 & -0.008 & $-0.027 ;$ to 0.004 \\
\hline & & Parental atopy - & -0.217 & 0.077 & -0.011 & 0.074 & 0.002 & -0.032 to 0.038 \\
\hline & Cesarean section & All & 0.121 & 0.039 & 0.063 & 0.045 & 0.008 & -0.003 to 0.022 \\
\hline & & Parental atopy + & 0.138 & 0.050 & 0.100 & 0.057 & 0.014 & -0.002 to 0.036 \\
\hline & & Parental atopy - & 0.087 & 0.064 & -0.011 & 0.074 & -0.001 & -0.019 to 0.016 \\
\hline \multirow[t]{6}{*}{ IgE, air } & Vaginal home delivery & All & -0.126 & 0.045 & 0.063 & 0.045 & -0.008 & -0.023 to 0.003 \\
\hline & & Parental atopy + & -0.078 & 0.057 & 0.078 & 0.068 & -0.006 & -0.025 to 0.006 \\
\hline & & Parental atopy - & -0.217 & 0.077 & 0.016 & 0.107 & -0.003 & -0.055 to 0.046 \\
\hline & Cesarean section & All & 0.121 & 0.039 & 0.063 & 0.045 & 0.008 & -0.003 to 0.022 \\
\hline & & Parental atopy + & 0.138 & 0.050 & 0.078 & 0.068 & 0.011 & -0.008 to 0.035 \\
\hline & & Parental atopy - & 0.087 & 0.064 & 0.016 & 0.108 & 0.001 & -0.023 to 0.028 \\
\hline
\end{tabular}

Boldfaced text indicates statistically significant mediation.

* Standardized coefficient of the association between mode of delivery and $C$ difficile.

$\dagger$ Standardized coefficient of the association between $C$ difficile and study outcomes (note that the $b$ path is also adjusted for mode of delivery).

$\lceil$ Product of the standardized coefficients of the $a$ and $b$ paths (mediated effect) and asymmetric 95\% CIs.

$\S$ Versus vaginal hospital delivery

$\| P<.05$. 
mode and allergies. Studies that extensively profile the whole neonatal GM composition are needed to further unravel the role of the GM composition in the relation between birth mode and allergic diseases. Such studies could add additional mediating mechanisms by other microorganisms and provide new leads for the primary prevention of allergies.

We thank all of the families that participated in the KOALA study.

\section{Key messages}

- This is the first study to demonstrate that infant gut microbiota composition is not only associated with early atopic manifestations, such as eczema and wheeze, but also with asthma.

- Gut microbiota composition and mode and place of delivery are both associated with the development of atopic manifestations, including asthma, mainly in children with a positive family history of atopy.

- The mediating role of $C$ difficile in the association between type of birth and atopic manifestations strengthens the evidence for a causal pathway.

\section{REFERENCES}

1. Bjorksten B, Sepp E, Julge K. Allergy development and the intestinal microflora during the first year of life. J Allergy Clin Immunol 2001;108:516-20.

2. Watanabe S, Nariswa Y, Arase S, Okamatsu H, Ikenaga T, Tajiri Y, et al. Differences in fecal microflora between patients with atopic dermatitis and healthy control subjects. J Allergy Clin Immunol 2003;111:587-91.

3. Kalliomäki M, Kirjavainen P, Eerola E, Kero P, Salminen S, Isolauri E. Distinct patterns of neonatal gut microflora in infants in whom atopy was and was not developing. J Allergy Clin Immunol 2001;107:129-34.

4. Penders J, Thijs C, van den Brandt PA, Kummeling I, Snijders B, Stelma FF, et al. Gut microbiota composition and development of atopic manifestations in infancy: the KOALA Birth Cohort Study. Gut 2007;56:661-7.

5. Romagnani $\mathrm{S}$. The increased prevalence of allergy and the hygiene hypothesis: missing immune deviation, reduced immune suppression, or both? Immunology 2004;112:352-63.

6. Rook GA, Brunet LR. Microbes, immunoregulation, and the gut. Gut 2005;54: 317-20.

7. Bjorksten B, Naaber P, Sepp E, Mikelsaar M. The intestinal microflora in allergic Estonian and Swedish 2-year-old children. Clin Exp Allergy 1999;29:342-6.

8. Penders J, Stobberingh EE, van den Brandt PA, van Ree R, Thijs C. Toxigenic and non-toxigenic Clostridium difficile: determinants of intestinal colonisation and role in childhood atopic manifestations. Gut 2008;57:1025-6.

9. Bager P, Wohlfahrt J, Westergaard T. Caesarean delivery and risk of atopy and allergic diseases: meta-analyses. Clin Exp Allergy 2008;38:634-42.

10. Thavagnanam S, Fleming J, Bromley A, Shields MD, Cardwell CR. A metaanalysis of the association between Caesarean section and childhood asthma. Clin Exp Allergy 2008;38:629-33.
11. Dominguez-Bello MG, Costello EK, Contreras M, Magris M, Hidalgo G, Fierer N, et al. Delivery mode shapes the acquisition and structure of the initial microbiota across multiple body habitats in newborns. Proc Natl Acad Sci U S A 2010;107: 11971-5.

12. Grönlund MM, Lehtonen OP, Eerola E, Kero P. Fecal microflora in healthy infants born by different methods of delivery: permanent changes in intestinal flora after cesarean delivery. J Pediatr Gastroenterol Nutr 1999;28:19-25.

13. Bezirtzoglou E. The intestinal microflora during the first weeks of life. Anaerobe 1997;3:173-7.

14. Penders J, Thijs C, Vink C, Stelma FF, Snijders B, Kummeling I, et al. Factors influencing the composition of the intestinal microbiota in early infancy. Pediatrics 2006;118:511-21.

15. Fallani M, Young D, Scott J, Norin E, Amarri S, Adam R, et al. Intestinal microbiota of 6-week-old infants across Europe: geographic influence beyond delivery mode, breast-feeding, and antibiotics. J Pediatr Gastroenterol Nutr 2010;51:77-84.

16. Bastiaanssen JM, de Bie RA, Bastiaenen CH, Heuts A, Kroese ME, Essed GG, et al. Etiology and prognosis of pregnancy-related pelvic girdle pain; design of a longitudinal study. BMC Public Health 2005;5:1

17. Kummeling I, Thijs C, Penders J, Snijders BE, Stelma F, Reimerink J, et al. Etiology of atopy in infancy: the KOALA Birth Cohort Study. Pediatr Allergy Immunol 2005; $16: 679-84$

18. Asher MI, Keil U, Anderson HR, Beasley R, Crane J, Martinez F, et al. International Study of Asthma and Allergies in Childhood (ISAAC): rationale and methods. Eur Respir J 1995;8:483-91.

19. Bindels PJ, Grol MH, Ponsioen BP, Salomé PL, Wiersma T, Goudswaard AN, et al Summary of the practice guideline 'Asthma in children' (second revision) from the Dutch College of General Practitioners. Ned Tijdschr Geneeskd 2008;152:550-5.

20. Stallman PJ, Aalberse RC. Estimation of basophil-bound IgE by quantitative immunofluorescence microscopy. Int Arch Allergy Appl Immunol 1977;54:9-18.

21. Aalberse R, Koshte V, Clemens JG. Immunglobulin E antibodies that crossreact with vegetable foods, pollen, and Hymenoptera venom. J Allergy Clin Immunol 1981;68:356-64.

22. Stapel SO, Eysink PED, Vrieze J, Aalberse RC. IgE testing in capillary blood. Pediatr Allergy Immunol 2004;15:230-3.

23. Akkerdaas JH, Wensing M, Asero R, Rivas MF, Knulst AC, Bolhaar S, et al. IgE binding to pepsin-digested food extracts. Int Arch Allergy Immunol 2005;138: 203-8

24. Roduit C, Scholtens S, De Jongste JC, Wijga AH, Gerritsen J, Postma DS, et al Asthma at 8 years of age in children born by caesarean section. Thorax 2009;64: 107-13.

25. Eggesbo M, Botten G, Stigum H, Nafstad P, Magnus P. Is delivery by cesarean section a risk factor for food allergy? J Allergy Clin Immunol 2003;112:420-6.

26. Maitra A, Sherriff A, Strachan D, Team AS, Henderson J. Mode of delivery is not associated with asthma or atopy in childhood. Clin Exp Allergy 2004;34:1349-55.

27. MacKinnon DP. Introduction to statistical mediation analysis. Mahwah (NJ): Erlbaum; 2008 .

28. Tofighi D, Mackinnon DP. RMediation: an R package for mediation analysis confidence intervals. Behav Res Methods 2011[Epub ahead of print].

29. Leadbitter P, Pearce N, Cheng S, Sears MR, Holdaway D, Flannery EM, et al. Relationship between fetal growth and the development of asthma and atopy in childhood. Thorax 1999;54:905-10.

30. Fergusson DM, Crane J, Beasley R, Horwood LJ. Perinatal factors and atopic disease in childhood. Clin Exp Allergy 1997;27:1394-401.

31. Bernsen RMD, De Jongste JC, Koes BW, Aardoomz HA, Van der Wouden JC. Perinatal characteristics and obstetric complications as risk factors for asthma, allergy and eczema at the age of 6 years. Clin Ex Allergy 2005;35:1135-40.

32. MacKinnon DP, Fairchild AJ, Fritz MS. Mediation analysis. Ann Rev Psychol 2007:58:593-614. 


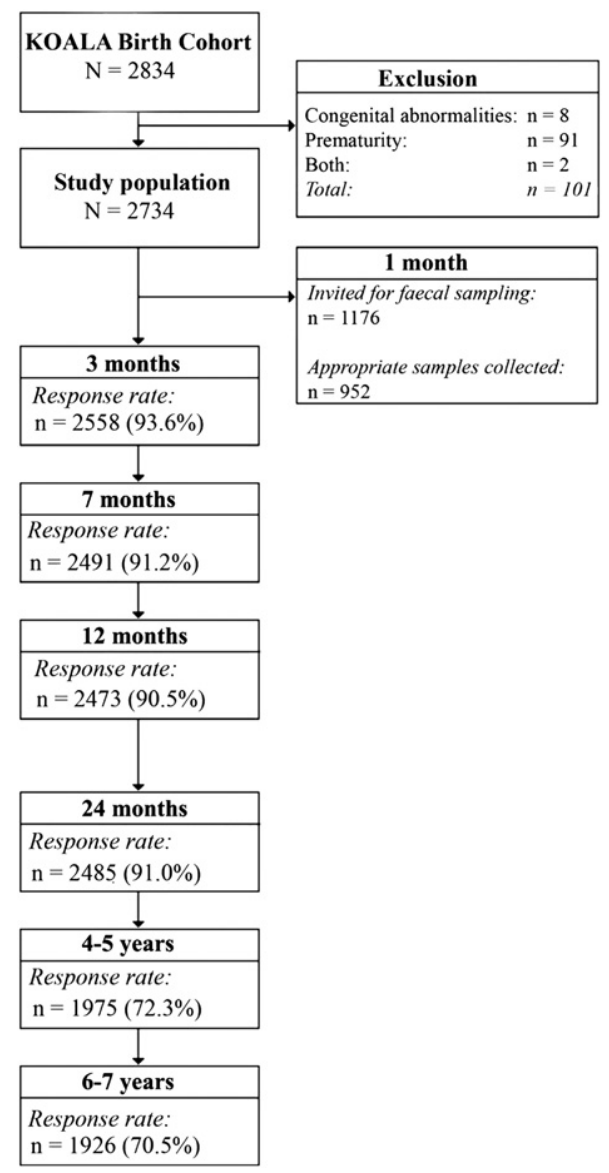

FIG E1. Population flow chart. 
Prevalence of wheeze

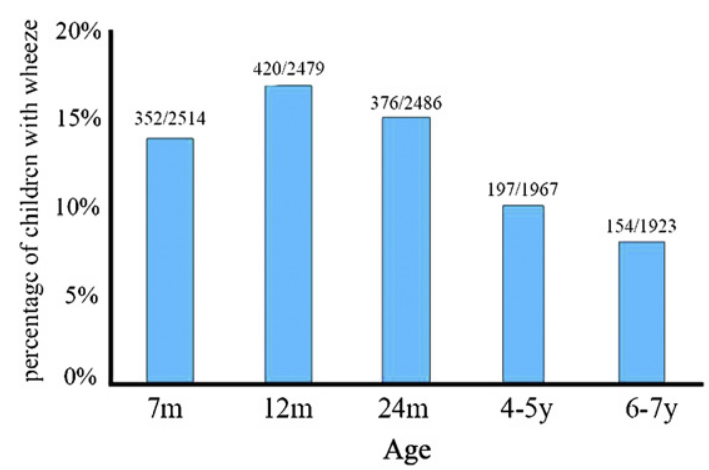

FIG E2. Prevalence of wheeze. 


\section{Prevalence of eczema}

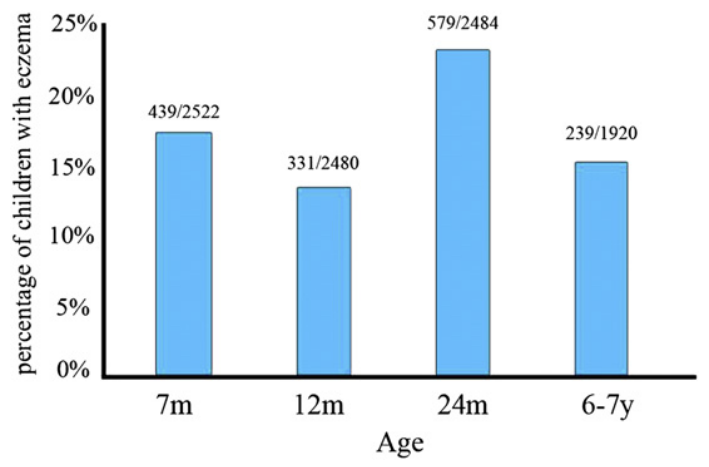

FIG E3. Prevalence of eczema. 